\title{
Appropriate assessment of disparity in some electrical parameters of selected bulbs
}

\author{
Ikwunze Okechukwu S 1, Okparaku Victor I 2,* and Igbokwe Kelechi $\mathrm{K}^{3}$ \\ ${ }^{1}$ Department of Electrical/Electronic Engineering, Abia State Polytechnic, sAba, Abia State, Nigeria. \\ 2 School of Science and Engineering Technology, Uma Ukpai Polytechnic, Asaga, Ohafia, Abia State, Nigeria. \\ ${ }^{3}$ Department of Physics/Electronics, Abia State Polytechnic, Aba, Abia State, Nigeria.
}

Global Journal of Engineering and Technology Advances, 2021, 09(02), 047-053

Publication history: Received on 13 October 2021; revised on 16 November 2021; accepted on 18 November 2021

Article DOI: https://doi.org/10.30574/gjeta.2021.9.2.0153

\begin{abstract}
The complaints, worries and dissatisfactions accrued to bulb users prompted the quest of this research. The objective of the research is to suitably assess few electrical parameters of bulbs available in the market in order to have an experimental proof of the disparity in their ratings. In the research experimental data, incandescent bulbs (100W and 200W), LED bulb (5W) and CFL bulb (40W) (of different powers) were selected for evaluation. The power and lux of the bulbs were measured and compared correspondingly using the incandescent bulbs as reference bulbs for lux comparison. The new double T8 full range \& ac/dc power meter with dimmer was instrument used to measure power and other associated electrical parameters (current and voltage) of the bulbs. The measurement results show that incandescent bulb of $100 \mathrm{~W}$ measured $60.1 \mathrm{~W}$ and the $200 \mathrm{~W}$ measured $184.0 \mathrm{~W}$. The power of the $5 \mathrm{~W}$ LED and $40 \mathrm{~W}$ CFL bulbs measured $7.2 \mathrm{~W}$ and $22.2 \mathrm{~W}$ respectively. On this note, it is invariably obvious that there exists disparity in power rating of the bulbs accessible in our present day market. The digital luxmetre was used to measure lux (luminous flux per unit area or lumen per metre square) of the bulbs. In the lux measurement, the luxmetre's sensor was placed $50 \mathrm{~cm}$ away from the bulb's position to obtain exact or close values to original bulbs' lux. Consequential to the bulbs lux comparisons, the lux value of 5W LED and 40W CFL bulbs have illuminances of 507lm/m2 and 568lm/m2 respectively higher than lux of 100W incandescent bulb. Hence, lux values of the LED and CFL bulbs measurements fall in-between lux values of $100 \mathrm{~W}$ and $200 \mathrm{~W}$ incandescent bulbs. Critical evaluation of the results tends to establish that luminosity (luminous flux per area) of bulb does not depend on power.
\end{abstract}

Keywords: Electrical power; Lux; Bulbs; Disparity; Measurement

\section{Introduction}

The understanding of the world around us is achieved with the help of information reaching our five sense instruments (organs), namely: eyes, ears, nose, tongue and skin. The sense associated with eyes is known as vision (or sight). Light is the agent which stimulates our sense of sight. The eyes convert the incoming light into electrical signals and convey them to the brain, which after processing the signals causes images or pictures to be created in our mind. According to Isaac Newton in 1675, in a corpuscular theory: a luminous body emits in all directions streams of extremely minute particles called corpuscles. Visible range is part of the spectrum constituted by waves, which can be detected by human eye. It extends from deepest violet to the deepest red. The limiting range of these waves depends in the individual properties of the eye and varies approximately in the interval $\lambda=4000 \mathrm{~A}^{0}$ to $\lambda=7800 \mathrm{~A}^{0}$ [2].

Perceptions of colour and appearance are multifaceted and psychological phenomena. Light can be defined as electromagnetic radiation with high possibility of affecting the sense of sight. For reliable assurance of a certain visual

\footnotetext{
${ }^{*}$ Corresponding author: Okparaku, Victor I

School of Science and Engineering Technology, Uma Ukpai Polytechnic, Asaga, Ohafia, Abia State, Nigeria. 
comfort, lighting sources must emit a certain luminous flux. When acquiring a specific source, its nominal data are marked on the box, including the light output [1].

Results of tests conducted on various sources with the same technical features has established that for the acquired light source, the luminous flux value marked on the box do not agree with the measured value. There are situations where the value of the emitted flux by a certain source of lighting is not part of the nominal data and is necessary to be determined. This determination is necessary in order to establish the aging degree of the source and whether it should be replaced. It can be achieved by measuring the flux values issued in different time intervals. Preserving or continuous use of a lighting source that is no longer capable to emit a corresponding visual luminous flux causes discomfort and unnecessary electricity consumption [8]. On this note, therefore, it is deemed fit for certain applications and its necessity to determine the actual value of the light output of the light sources. The lighting energy efficiency increase should be necessarily done from time to time to measure the luminous flux emitted by different sources so that light energy of poor efficiency can be replaced in time.

The sensational effect of light is dependent on the radiation spectrum wavelength, $\lambda$, according to the relative visibility. The luminous flux is dependent radiant power (energy flow $\Phi_{\mathrm{e}}$ ), through the relative visibility curve of the normal eye. The measurement unit of the luminous flux is a radiated watt per $0.555 \mu \mathrm{m}$ wavelength, called watt light (Wl) [11]. In the international system (IS) the measuring unit for flux is lumen [lm] and one-watt light is equal to $683 \mathrm{~lm}$. The unit of measurement of illumination in the international system is lux [lx] and it is defined as illumination of an area that receives a luminous flux of one lumen having a uniformly distribution over a surface of $1 \mathrm{~m}^{2}$ [6] [9].

The light level is measured using an luxmeter. This is based on the action of the light on a photosensitive element. Lumen represented by $\mathrm{lm}$ is the SI derived unit of luminous flux that measures the total quantity of visible light emitted by a source per unit of time. Luminous flux differs from power (radiant flux). The radiant flux includes all electromagnetic waves emitted, while luminous flux is weighted according to a model (a luminosity function) of the human eye's sensitivity to various wavelengths. The $26^{\text {th }}$ General Conference on Weights and Measures (CGPM) redefined the photometric units in 2018 which took effect on May $20^{\text {th }}, 2019$ [10]. Based on the new definition, lumens and lux are related in that one lux is one lumen per square metre. But before 2019, the definition was based on Candela (cd) as [7].

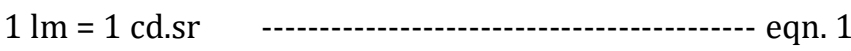

Where,

$\mathrm{Lm}=$ lumen; $\mathrm{cd}=$ candela; and $\mathrm{sr}=$ steradian.

In this research, selected and known bulbs/lamps are going to be used in the experiment for clarity and better understanding of the results and further suggestions. Amongst the types of bulb available in the market in our area or location, the three types of bulb that would be applied are the Incandescent, LED, and CFL bulbs/lamps.

An incandescent bulb typically comprises a glass enclosure containing a tungsten filament. When an electric current is passed through the filament, it is heated to a temperature that produces light. The enclosing glass enclosure contains either a vacuum or an inert gas to preserve and protect the filament from evaporating [12] [13].

LED lamp or LED light bulb is an electric light that produces light using light-emitting diodes (LEDs). LED lamps are significantly more energy-efficient than corresponding incandescent lamps and can be significantly more efficient than most fluorescent lamps [3] [5].

A compact fluorescent lamp (CFL), also known as compact fluorescent light, energy-saving light and compact fluorescent tube, is a fluorescent lamp designed to replace an incandescent light bulb. In the intervening time, some types of CFL fit into light fixtures designed for incandescent bulbs. CFLs produce light differently than incandescent bulbs. In a CFL, an electric current is driven through a tube containing argon and a small amount of mercury vapor. This generates invisible ultraviolet light that excites a fluorescent coating (called phosphor) on the inside of the tube, which then emits visible light [4].

Regarding the incandescent bulbs, 100 watts and 200 watts' bulbs would be used as the two extreme (intervals) for comparison with 5 watts LED and 40 watts CFL. Outside the power disparity evaluation, the lux values of 5 watts LED and 40 watts CFL bulbs would be compared to 100 watts and 200 watts' incandescent bulbs. 


\section{Instruments (Materials) Of Measurement}

\subsection{Digital Luxmetre}

The value of the luminous flux can be measured using the photometer integrator known as Ulbricht lumen meter, which consists of an empty metal or fiberglass sphere, painted in interior with matt, very fine grain white colour, that produces a multiple diffuse reflectance. The white colour used for painting the photometer is characterized by a certain reflection factor $r$.

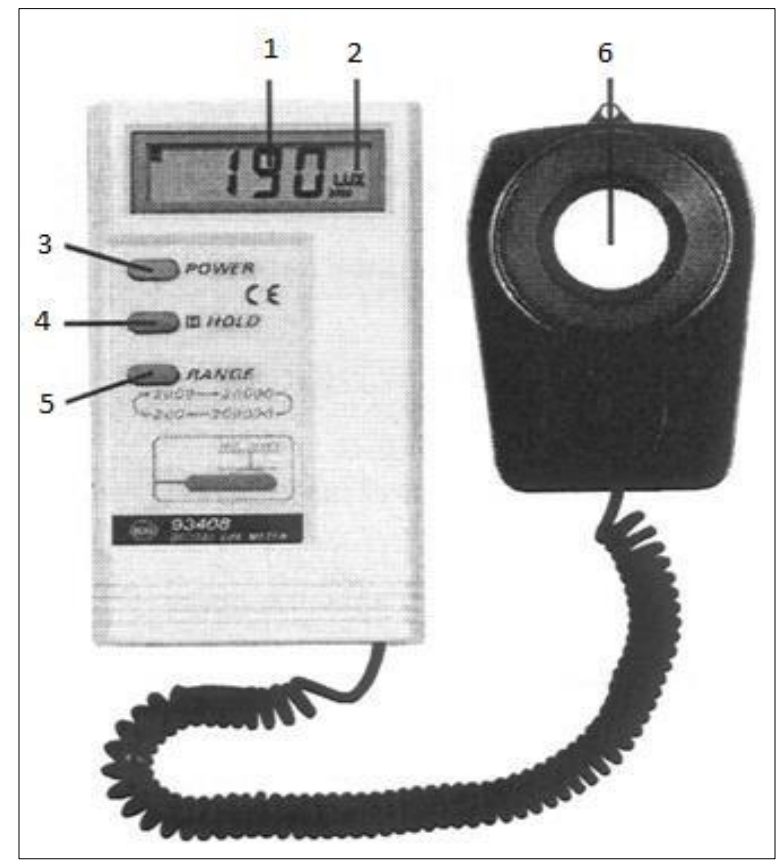

Figure 1 Digital Luxmetre

The luxmetre is composed of the following components

- LCD display

- display measuring range

- start button

- data memory button

- choice button

- $\quad$ Sensor (photodiode with silicon).

This digital lux meter used in this experiment has four measuring ranges of lux: $0-20,0-200,0-2000$ and $0-20000$, with the corresponding errors to the four areas being $0.01,0.1,1.0$ and 10.0 .

\subsection{New Double T8 Full Range \& AC/DC Power Meter with Dimmer (Model No.: LT-1396F)}

The input voltage of this power meter Is AC $90 \mathrm{~V}-265 \mathrm{~V} / \mathrm{DC} 12 \mathrm{~V}$. The output voltage is the same as input voltage. The power meter could test any electric appliance among AC 90V-265V/DC $12 \mathrm{~V}$. The tester could test not only the lighting products (LED lamps, CFL energy saving lamps, halogen lamps) but also the other electric appliance. Maximum testing wattage: AC 300W, DC 60W. Testing parameters include voltage, current, wattage, power factor, annual power consumption and annual bill. It is convenient to use with multi-use sockets, and could test the appliance with power plug of different countries. It is no need to connect the wire in addition.

With different base: AC part contains 2pcs E27, 2pcs B22, 2pcs G24, 2pcs E14, 2pcs GU10, 2pcs B15, 2pcs G9, 2pcs AC multi-use sockets, 2 sets of terminal holder and 2 sets of tube connectors. DC part contains 2pcs MR16, and 2 sets terminal holder, so it could test different lamps with different bases. Having 2 dimmers on tester, it tests the dimmable lamps also. 
It compares 2 lamps or 2 tubes at same time with 2 sets display windows to show the data. The appliance could be tested by connecting the wires with terminal holder on the tester. With fuse in power sockets, it could protect load short circuit.

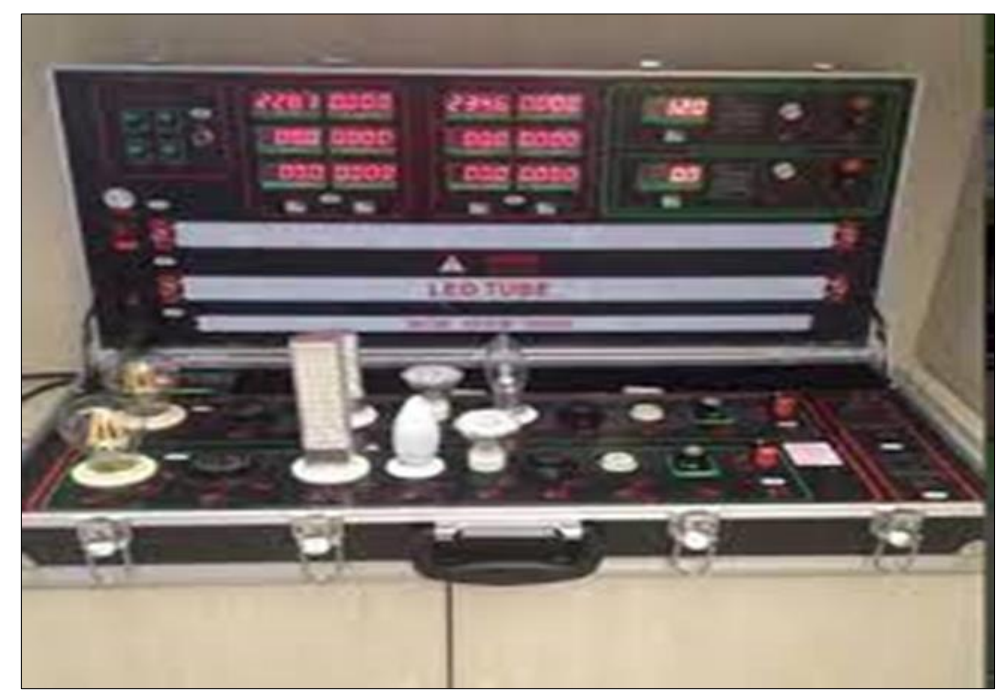

Figure 2 New double T8 full range \& ac/dc power meter with dimmer

\subsection{Acquisition of bulb}

The bulbs used in the research were acquired from the electrical appliance shop in the market. They are not supplied direct from the manufacturer. Different bulb types were acquired and hence, 100 watts and 200 watts incandescent, 5 watts LED and 40 watts CFL were selected based on their comparable flux values.

\subsection{Images (Samples) Of Used Bulbs}

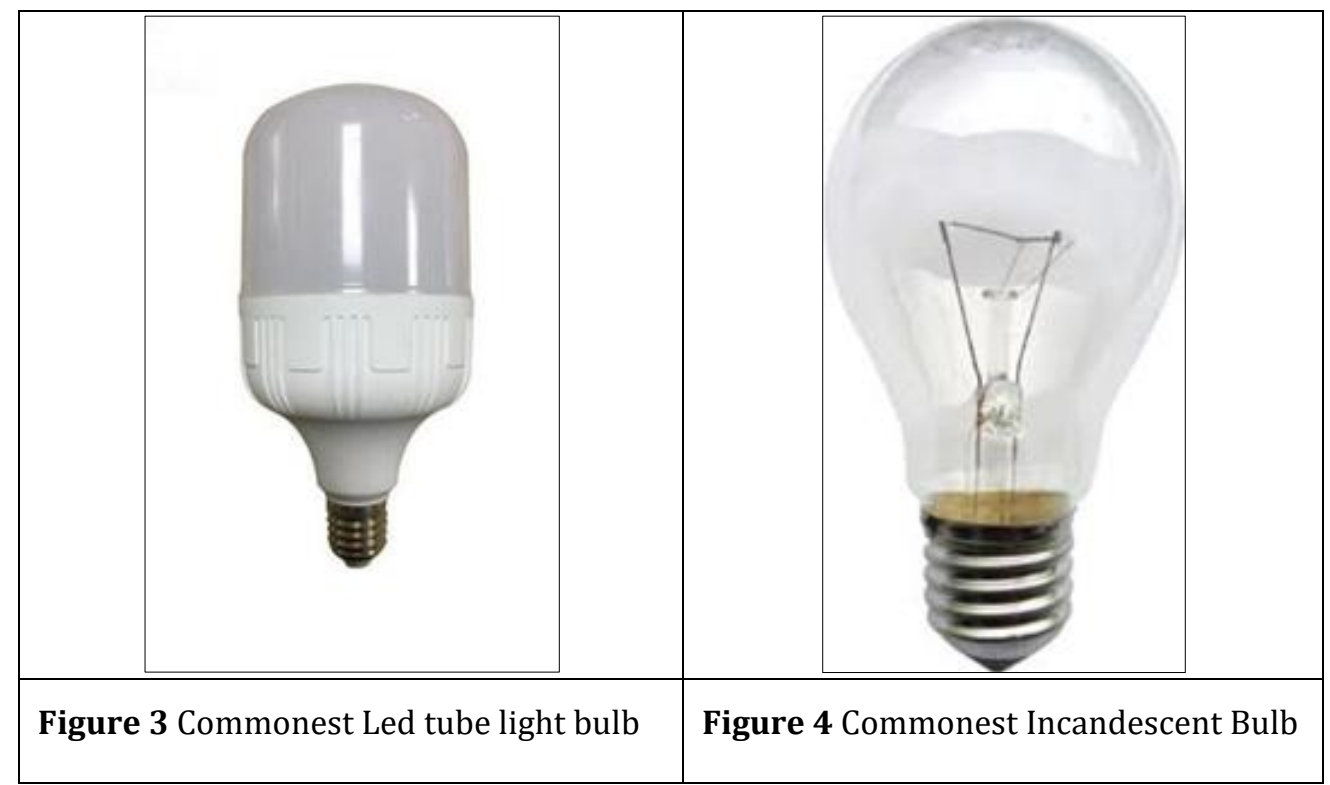




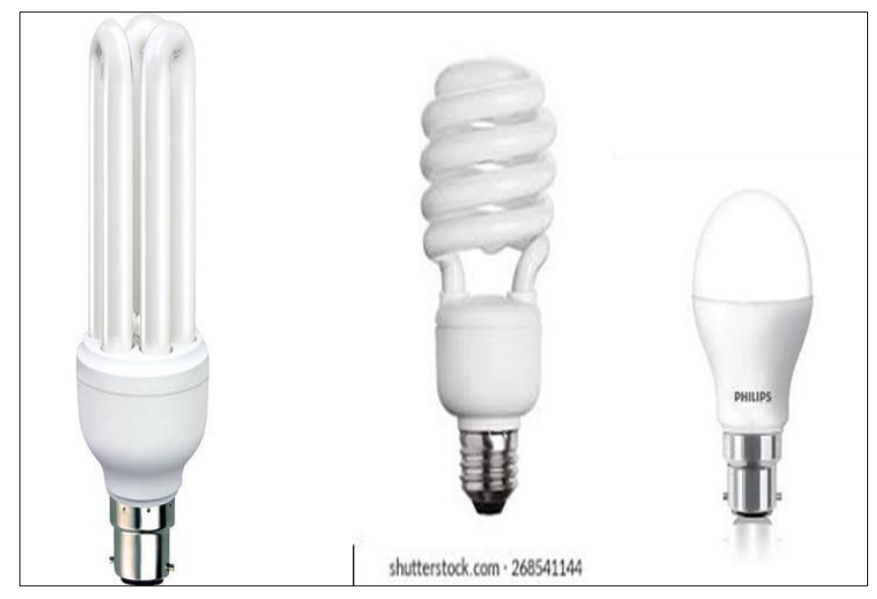

Figure 5 The three common Compact Fluorescent Lamps

\subsection{Technique of experiment}

\subsubsection{Step 1}

The digital luxmetre was used here to measure lux of all the bulbs acquired from the market. In the process of the measurement, the sensor cap was opened before taking reading. For accurate values the luxmetre's sensor was placed $50 \mathrm{~cm}$ away from the light source (the bulb) for all the bulbs. When the bulb was fixed or connected in the power metre and the metre switched on, a metre rule was used to measure a $50 \mathrm{~cm}$ distance from the light source while the digital luxmetre was applied to record the lux of the bulbs in luminous flux (lumen) per $\mathrm{m}^{2}$.

\subsubsection{Step 2}

The 100 wats and 200 watts incandescent bulbs were picked and compared. The two bulbs were connected to the power metre at band A and B and the metre was switched on as their different electrical parameters such as power, voltage and current were recorded directly from the power metre. Afterwards, the measurements were conducted for 5 watts LED and 40 watts CFL in same power metre.

\section{Experimental results and discussions}

The following are results of the experiments recorded of 100 watts and 200 watts' incandescent bulbs, 5 watts LED bulb and 40 watts CFL bulb.

\subsection{Results on the bulbs' electrical parameters}

Voltage of source $=219.5 \mathrm{~V}$

Table 1 Results of some electrical parameters of 100W and 200W incandescent (reference) bulbs

\begin{tabular}{|c|c|c|c|c|}
\hline Normal (original) Values & \multicolumn{4}{|c|}{ Measured Values } \\
\hline Power (Watts) & Lux (lm/ m²) & Power (Watts) & Voltage (V) & Current (A) \\
\hline 100 & 308 & 60.1 & 219.2 & 0.268 \\
\hline 200 & 867 & 184.0 & 218.7 & 0.841 \\
\hline
\end{tabular}

Table 2 Results of some electrical parameters of 5W LED and 40W CFL bulbs

\begin{tabular}{|l|l|c|c|c|c|}
\hline \multirow{2}{*}{ Bulb Type } & Normal (original) Values & \multicolumn{4}{|l|}{ Measured Values } \\
\cline { 2 - 6 } & Power (Watts) & Lux (lm/ m²) & Power (Watts) & Voltage (V) & Current (A) \\
\hline LED & 5 & 507 & 7.2 & 219.4 & 0.120 \\
\hline CFL & 40 & 568 & 22.2 & 219.4 & 0.325 \\
\hline
\end{tabular}




\subsection{Discussion of power disparity of the selected bulbs}

From the data representation of table 1 above, it could be grasped that power of $100 \mathrm{~W}$ incandescent bulb measured $60.1 \mathrm{~W}$ which is about $39.9 \mathrm{~W}$ lower than the actual (normal) or manufacturer claimed power and the power of $200 \mathrm{~W}$ incandescent bulb measured 184.0W which lacks the actual value by $16.0 \mathrm{~W}$ against the claim of the manufacturer.

According to data of table 2 as represented above, the power of 5W LED bulb/tube measured 7.2W as contrary to the manufacturer's claimed power value of the bulb which differed by $2.2 \mathrm{~W}$. On the other hand, the power of $40 \mathrm{~W}$ CFL measured 22.2W against the prerogative value of the bulb with difference of $17.8 \mathrm{~W}$.

The two experimental results revealed that lots of bulbs in the market today are mendacities of the manufacturers' designated worth or values. These falsified specifications had made the users to encounter difficulties in balancing the power input and output of their household power sources and appliances, especially people that generate their energy from clean energy (renewable energy) or mechanical/chemical effects (such as in generator set). The danger of this falsehood affects the energy consumers of national grid (for example, EEDC in Nigeria) whose monthly energy consumption bills are mostly charged by estimations and not energy meter reading based and, also it could affect the EEDC revenue. Therefore, the most users of illuminating source (bulb) are being skeptical about reliability of bulb in the market.

\subsection{Discussion of comparative nature of the selected bulbs' lux}

Lux of the selected three bulb types as measured will be compared here to ascertain the factors of its depictions. The two incandescent bulbs of powers $100 \mathrm{~W}$ and $200 \mathrm{~W}$ were measured as reference bulbs to compare their brightness, known as the luminous flux (measured in lumen), with 5W LED and the 40W CFL. Measurement of flux is unswervingly an understanding of the brightness of a bulb.

Considering the measured lux of the bulbs, we can see that $100 \mathrm{~W}$ incandescent bulb measured $307 \mathrm{~lm} / \mathrm{m}^{2}$ and the $200 \mathrm{~W}$ incandescent bulb measured $887 \mathrm{~lm} / \mathrm{m}^{2}$. Let the lux results of the incandescent bulbs be considered to establish a comparison. The lux value of $5 \mathrm{~W}$ LED bulb measured $507 \mathrm{~lm} / \mathrm{m}^{2}$ which is greater than value of $100 \mathrm{~W}$ incandescent bulb $\left(307 \mathrm{~lm} / \mathrm{m}^{2}\right)$ and below value of $200 \mathrm{~W}$ incandescent bulb $\left(887 \mathrm{~lm} / \mathrm{m}^{2}\right)$. This result shows that the lux of $5 \mathrm{~W}$ LED bulb falls in-between the lux values of $100 \mathrm{~W}$ and the $200 \mathrm{~W}$ incandescent bulbs. However, it is clearly evident that the brightness or illuminance of $5 \mathrm{~W}$ LED bulb is greater than $100 \mathrm{~W}$ incandescent bulb despite its lesser power value. Therefore, luminous flux (brightness) is not power dependent since a 5W LED could produce more a visible light than a $100 \mathrm{~W}$ incandescent bulb.

The lux value of $40 \mathrm{~W}$ CFL bulb measured $568 \mathrm{~lm} / \mathrm{m}^{2}$ which is of greater value to $100 \mathrm{~W}$ incandescent bulb. Despite the difference in power of the two bulbs, yet, the lux value of CFL out-measured the incandescent bulb. This is convenient evidence to receive that lux (luminous flux per unit area) of bulb is not power dependent.

The outcomes of the experiment had shown that in general concept, power is not a determinant of values of luminous flux. The only condition when power is a factor of bulb's lux is when it concerns a bulb manufacturing company in whose bulb's illuminance differs by their powers

\section{Conclusion}

The bulbs available in today's market are insufficiently having their claimed power rating. In fact, bulb manufacturers are playing pranks in bulb manufacturing. They defraud money from their bulbs users by manufacturing bulbs whose power rating are below their claimed values.

On the other hand, LED and CFL bulbs have greater lux values than the incandescent bulb and that is why their brightness (visible light emission) is far beyond what incandescent bulbs could emit. The outcomes of the experiments displayed a glaring fact that lux does not depend on power, though manufacturers use power to differentiate their products (bulbs) lux.

\section{Suggestion}

The bulb manufacturers should change their manufacturing pattern of ratings to accommodate and address the shortfalls in values of the bulbs' electrical parameters. In other words, it is suggested that bulb manufacturers instead of been exact in their ratings should rather have a range of values as specifications. For example, a bulb of power rating of $100 \mathrm{~W}$ could be specified with a rating of $60 \mathrm{~W}-100 \mathrm{~W}$ attributed to the bulbs that were used in the experiment. 
However, LED and CFL bulbs should be considered for areas (households, event centres, etc.) that need more illuminance because they conserve more energy notwithstanding their high illumination.

\section{Compliance with ethical standards}

\section{Disclosure of conflict of interest}

No conflict of interest.

\section{References}

[1] Asim Kumar Roy Choudhury. Principles of Colour and Appearance measurement: Object Appearance, Colour Perception and Instrumental Measurement. Woodhead publishing. 2014.

[2] Avadhanulu MN. A Textbook of Optics. S. Chand \& Company PVT. Ltd. Ram Nagar, New Delhi. 2008.

[3] Elisabeth Rosenthal and Felicity Barringer. Green promise seen in switch to LED lighting. The New York Times. 2009.

[4] Energy Star Program Requirements for CFLs Partner Commitments. $4^{\text {th }}$ edition. 2008.

[5] Lin Judy. The next generation of LED filament bulbs. LED Inside. 2015.

[6] Mogoreanu N. Iluminatul electric, Editura Lumina, Chișinău, Moldavia. 2013.

[7] Nakamura S, Mukai, Senoh M. Candela-class high-brightness InGaN/lGan Double-Heterostructure blue-lightemitting-diodes. Applied physics letyters. 1994; 64(13): 1687.

[8] Pentiuc RD, Vlad V, Lucache DD, Pavel S. Street Lighting Power Quality, 8th International Conference and Exposition on Electrical and Power Engineering EPE 2014, Iaşi, Romania, October. 2014; 16-18: 1107-1110.

[9] Piroi I. Instalații electrice și de iluminat, Editura Eftimie Murgu, Reșița, Romania. 2009.

[10] Rata G, Rata M, Prodan C. Analysis of the Deforming Regime Generated by Different Light Sources, using Reconfigurable System - Compact RIO, 8th International Conference and Exposition on Electrical and Power Engineering EPE 2014, Iaşi, Romania. October 2014; 16-18: 748-751.

[11] Spunei E, Piroi I, Piroi F. Optimizing Street Lighting Systems Designs, Analele Universității Eftimie Murgu Reșița, Fascicola de Inginerie. 2014; XXI (3): 257-268.

[12] Taub Eric. How long did you say that bulb would last? New York Times. 2009.

[13] U.S Department of Energy. Solid-state lighting gateway demonstration results. Archived at the way back machine. 2010. 